\title{
TENSÕES (DE)COLONIAIS EM CHUVA BRANCA, DE PAULO JACOB
}

\section{(DE)COLONIAL CONFLICTS IN CHUVA BRANCA BY PAULO JACOB}

Chuva Branca, romance do amazonense Paulo Jacob (1968), é tido como obra literária de destaque na Amazônia. Publicada em 1967, nos apresenta um protagonista (Luiz Chato) que anuncia um viés avesso à tradição da ficção latino-americana (Amazônia) ao trazer como tema a relação homem e natureza. No enredo, a trajetória de Luiz Chato insinua o desaparecimento da dicotômica hierarquia entre humanos e natureza na luta constante pelo domínio do espaço de (con)vivência na floresta. A abordagem que se propõe aqui realizar é no sentido de entender, ao estudar o personagem, os avanços apresentados no processo de desconstrução de imagens arquivos na literatura que moldaram o imaginário mundial dos povos colonizados que estão potencializados na contemporaneidade, sob
Maria de Nazaré Cavalcante de Sousa ${ }^{1}$

ponto de vista dos estudos da interculturalidade crítica (WALSH, 2006), uma abordagem que se distancia da razão cartesiana em relação corpo-objeto.

A obra está dividida em duas partes pelas quais a narrativa é conduzida e vivida pelo protagonista. Na primeira, Luiz Chato, invocando sobre sensações e impressões como morador daquelas terras, caminha em um domingo santo na espera de caçar uma anta, animal comum para alimento na região, e acaba perdendo-se na mata durante quarenta dias. Na segunda parte, o enredo se desenvolve quando se empenha em encontrar a estrada de volta para casa. A trama será narrada em primeira pessoa, traçando diálogo intradiegético, apostando na reconstituição vocabular do ser amazônico, um resgate gracioso do falar regional. Lembranças e reflexões de Luiz

Doutora em Teoria Literária pela Universidade Federal de Santa Catarina (2013) e professora da Universidade Federal do Acre. 
Chato quando anda em busca do retorno irão amarrando e tecendo um rosário linguístico, mitológico, medicinal, de costumes vastíssimos. 0 embate entre a cultura ocidentalizada e o bem viver com a natureza travam conquistas no diálogo com as heranças culturais advindas dos conhecimentos da mata e da cidade.

As imagens que o fazer literário constrói em Chuva Branca insinua que a experiência com a visualidade intervém de forma direta na conceituação de lugares, credos e simbologias humanas. São registros de imagens em conflito que se mantêm na contemporaneidade, o que torna por constituir uma crítica da modernidade-colonialidade, reificada em relação ao sujeito e natureza. Tais imagens reúnem padrões culturais e sociais que foram construindo através de préconceitos com a hierarquização exercida quanto à racionalidade e misticismo, visualidades que certamente tornam-se por ser mediadoras da realidade. A constituição e naturalização dessas outras imagens implementadas pelo eurocentrismo se encontram numa perspectiva que pensadores como Joaquin Barriendos denominará de colonialidade do ver. 0 deslocamento geográfico do fantástico medieval e do imaginário europeu se uniram à formação da história e da cultura na América Latina, e influenciaram decisivamente nas construções escritas e formação de imagens referendadas pela ciência e assumidas nas produções ficcionais de toda a América e, sobretudo, nos países que foram tornados independentes das metrópoles europeias. Os pensadores de coloniais assumem o papel de lutar para descontruir a versão instituída pelo europeu, trazendo ressignificações que possam retomar, rever, negociar traços intrínsecos ao ser dessas regiões.

Teóricos como Christian León (2010), que defende uma crítica decolonial para os estudos das visualidades, chama atenção para a importância de se considerar o papel das imagens como uma forma de pensar caminhos para desconstrução de uma hierarquia marcada entre o sistema visual ocidental e não ocidental implantados a partir 
de uma série de mecanismo tecnológicos, iconográficos, psicológicos e culturais integrados a sistemas coloniais de poder e conhecimento. Juntando-se à linha da escrita euclidiana, a criação literária, no período entre o final do século XIX e a metade do século $\mathrm{XX}$, trouxera algumas produções que preconizaram temáticas nesta perspectiva. São romances, contos que percebem o confronto da natureza dos migrantes e imigrantes que se aventuravam na floresta e que gerariam enredos que tendem impor a floresta como protagonista, ou antagonista, com metas punitivas contra os que intentam adentrá-la ou dominá-la. Transparecendo, nesse instante, na grande maioria dos romances, a preocupação de exaltação da cor local, enlaçando uma inclinação para manutenção da hiperbólica Amazônia já imaginada e divulgada em países europeus.

0 escritor Uruguaio Angel Rama assinala em sua obra ciudad letrada (1984) o vasto império instituído na América Latina que serviu como um campo de inúmeras experimentações da cultura colonizadora, ignorando a constituição do ser, do espaço e da cultura locais. Construir uma cidade na América implicava a construção de uma cultura colonial e canibalística, no processo de modelamento de um espaço para incluí-lo no Império. Essa é a imagem que existe da formação das cidades no imaginário. Rama pode ser incluído dentre os intelectuais que discutem esse processo de formação da colonialidade constitutiva da visualidade na América Latina, pensado o processo de transculturação cultural.

Algumas produções literárias foram a base para as recriações de narrativas audiovisuais, como o cinema, em um primeiro momento e, em seguida, a televisão, e que ainda permeiam imagens expostas em redes virtuais na primeira década do século XXI. A literatura que é produzida neste espaço ou sobre estes lugares da Amazônia, tomando Peru, Bolívia e Brasil, Venezuela, etc. tem se mantido ainda distante do que chamaríamos de uma virada decolonial. É provável que seja na arte em que mais se resiste ao enfrentamento de forma crítica das imagens e imaginários estabelecidos. 
No romance de Paulo Jacob, ainda que timidamente, é possível deparar-se com a imbricação entre sujeito e natureza subsistindo os valores e a hierarquias eurocêntricas. Nele, imagens estabelecidas no imaginário cultural dos povos amazônicas na colonialidade são postas à prova através do enfrentamento do ser amazônico, pessoa e lugar, em confronto com as adversidades de seu habitar. Há rastros em Chuva Branca com certa audácia de um embate com a instituição de verdade propagada e institucionalizada sobre a mata, sobre a religião cristã, absorvidos no processo decolonização do imaginário e da memória sociais.

Ao vivenciar dois mundos, o autor nos mostra a dificuldade do protagonista lidar com os referenciais 'civilizados' pelos quais fora educado, despindose visceralmente e só assim sobreviver às intempéries da mata. 0 tema enverada naturalmente para o descritivo, o canto do lugar, em que o homem e a natureza são colocados em situação de igualdade na luta pela sobrevivência. 0 narrador de Paulo Jacob avança quando sustenta todo o enredo em intermitente dialogar com a natureza, com o homem e os animais e a imprescindível imbricação destes, com leveza e interessantes construções metafórica.

A narrativa construída enlaça o leitor em descrição minuciosa do lugar, a fala de Luiz Chatos e caracteriza por mostrar um deslizar nostálgico pelo falar, pelo sentir e pelo ouvido do cotidiano amazônico:

Bicha gelada, é água de chuva com igarapé. Suja barrenta, pausada. Pisar a jeito, o pé arrastando no fundo, atenção com arraia. Tocando de leve na bicha, corre, não ferra. Eita! Puraqué filha da puta (JACOB, 1968, pp. 103/104).

O sol vai indo aqui. Quebrando o rumo mais à direita, sair no varadouro de tocar direto na mãe-do-rio. Nove ou dez horas, caminhada batida, dá pra chegar. Das oito, coizinha já passa. Tempão gasto mesmo foi na vinda, andando devagar, volteando demais... (JACOB, 1968, p. 47).

São conversas que soam, ruminam e rutilam na resistência de um povo que, como Luiz Chato, conhece as águas, os igarapés e o medo de arraias escondidas sob a lama e o perigo que dela advém. Ou como se aprende sob a orientação do tempo e dos varadouros no 
interior da mata, o sol baixando ou subindo, os rumos seguidos pela altura do sol.

Ao enfatizar o falar nativo, resgatando um vocabulário comum da oralidade pulsante, a obra permite resgate de uma herança com sensibilidade e respeito pelo mover-se entre os espaços, visualizando uma cosmovisão que subsiste de algum modo na contemporaneidade, mas que tende a ser suprimida por não fazer parte do vocabulário, imaginário e, principalmente, das visualidades globais. Há um olhar do tradicional, acoplado à modernidade, uma contemplação poética que pode congelar uma memória e tornar-se fascinante. É essa poesia que Luiz Chato provoca ao destrinchar esse vocabulário tão familiar e tão presente na memória do amazônida.

Lua crescente, escorregando para mais de metade do céu. Rasto de luz entrando aqui, escondendo acolá, vestígio mais largo ali bem. Tempão acordado, sem saber o que foi sono. Bocado de vezes inambu-relógio marcando instantes na noite. A barriga ôca, em jejum deu de perder sono, a cabeça enche de muitas coisas (JACOB, 1968, p. 181).

$\mathrm{Ou}$ :
Madrugada de mata tem cheiro de lacre, breeiro, catleia, baunilha, raiz, outros de que mais.... Nasce dia naquela alegria, canto de pássaro, ar molhado de sereno, friozinho gotejando. Até anima, esperança de alguma coisa boa (JACOB, 1968, p. 129).

Pensando a obra com traços de interculturalidade na visão de Catherine Walsh

A construção vocabular elucubrando sobre saudade, solidão, angústia, alegria, paixão utilizando os referenciais do lugar em constante embate com os referenciais urbanos faz de Chuva Branca uma promessa de ficção que trilha para a construção de um diálogo numa perspectiva de interculturalidade, principalmente, quando o protagonista, numa postura crítica, reavalia sua forma de falar, de imaginar sobre o lugar em que vive.

Chuva Branca, nesse caso, pode ser uma obra que aponta para uma leitura de interculturalidade crítica, por entender que esta faz parte da necessidade do diálogo e da compreensão e da demanda dos diferentes, assimila um tom diverso daquele que quer apenas marcar a sua diferença: parte da necessidade de se ver no espelho 
do outro e o outro se ver no meu espelho e, quem sabe, encontrar um mundo liberto das amarras de uma sociedade hierárquica, cujas identidades não tenham pretensões hegemônicas sobre as outras realidades culturais. A obra também traz o contraste da sabedoria da mata e o poder presumível dos conhecimentos adquiridos pelo homem 'civilizado'. 0 poder da civilização e suas leis especificas e incompreensíveis ao caboclo. Mitos de impedimentos da felicidade relacionados à cosmologia.

Em Chuva branca é possível encontrar um espaço individual que se localiza entre o mundo exterior e o mundo interior do personagem mostrando sentimentos e temores. Pode ser pensado no enredara importância da natureza na subjetividade humana, essa natureza que na colonialidade-modernidade está sob o controle epistemológico.

A interculturalidade em Chuva Branca não acontece no confronto com o outro, mas no confronto do sujeito com sua subjetividade diante de toda uma formação de absorção, imposições de ações da realidade em sua formação como indivíduo da mata que insurge para negar as construções simbólicas da mata, ou seja, de seu lugar de origem. $\mathrm{Na}$ luta do homem buscando resistir às intempéries do tempo, a narrativa é enriquecida pelo rosário mostrado sobre a medicina natural da Amazônia. A linguagem é uma recuperação das imagens, da memória, do vocabulário bem do ser que nasce e vive na Amazônia. A interculturalidade é concebida a partir do relacional. Luiz Chato resiste retomar os referenciais de sua origem, mas ao mesmo tempo percebe a necessidade de assumilos, pois intuitivamente esses referenciais é que possibilitam o seu retorno para casa. Com isso, o conflito interior é intenso diante das duas culturas que se manifestam dentro de si. Ele torna por negociar os referenciais por necessidade de sobreviver diante da encruzilhada da vida ou da morte.

A interculturalidade tem uma significação na América Latina ligada às formações geopolíticas do espaço, das lutas históricas e sociais. Mais que um conceito e inter-relação, ela proporciona e assinala o processo de construção 
de conhecimento do outro que se instalou nos diversos lugares desta América. Chuva Branca intrinsecamenteseconstróiapartir do entrelaçamento e do embate de culturas outras, dos choques, da aceitação, da recusa do outro em sua forma distinta de pensar. 0 enredo passa necessariamente pelo reconhecimento identitário da formação do ser e o ver, o verse (a minha imagem) diante do lugar que é seu, o narrar compõe as imagens.

Um dos pontos que se questiona, quando da vulgarização do conceito de interculturalidade, segundo Catherine Walsh, é a proposta da hegemonia geopolítica do conhecimento, que não busque simplesmente a associação da cultura com políticas identitárias, mas promova configurações conceituais que denotem outras formas de pensar e posicionar-se a partir das diferenças geradas pelo processo colonial, como formas necessárias para a construção de um mundo mais justo (WALSH, 2006).

\section{Em Chuva Branca,as} trocas culturais acontecem subjetivamente. Um monólogo, ou diálogo introspectivo de Luiz
Chato "civilizado" e o Luiz Chato "primitivo", e isto certamente é uma situação conflitiva no percurso de elaboração do personagem pelo autor da obra. 0 enfoque e a prática de interculturalidade defendida na ficção são construídos numa angustiosa mutilação de verdades, de referentes, de aprendizados, de nulidade e adversidades que se consome, estão presentes atualmente nas relações culturais na América latina.

0 protagonista é conduzido pelo lugar e ao mesmo tempo domina o espaço em que se encontra. Luiz Chato vai adentrando, vai assimilando a floresta, vai se afastando do que se denomina civilização, até parecer que não mais existe enquanto ser cultural, está integrado, é natureza, é tudo natureza, é pachamama, é um ser buen vivir. Não toca nas causas das assimetrias ou constrói uma narrativa que induz, mais propõe, de forma reflexiva, a necessidade de negociação e de respeito pela tradição, que a todo tempo está referendado em suas reflexões ou monólogo interior, tanto faz. Portanto, Chuva Branca,através de um diálogo de interculturalidade, aponta 
nuances críticas sobre o contexto e dominando-a e sendo dominado o ser, possibilitando apontara obra por ela. 0 fluxo natural da relação como uma alternativa na busca de entre vidas. criações com viés que desbanque Referências a visualidade estabelecida como JACOB, P. H. M. Chuva Branca. Rio homogênea e, com isso, a literatura de Janeiro: Gráfica Record Editora, produzida sobre e na Amazônia. 1968.

Uma literatura que deve contribuir para a análise da latino-americana em sua geopolítica e geo-cultura e o ser imbricado com a natureza, não apavorado com a floresta misteriosa, mas encontrando-a, LEÓN, C. Desenganche visualidades y sonoridades otras - La Tronkal. Quito, Equador, 2010. WALSH, C. Interculturalidad, descolonización del estado y del conocimento. Buenos Aires: Del Signo, 2006. 